\title{
An energy-efficient metro speed profiles for energy savings: application to the Valencia metro \\ Ignacio Villalba Sanchis
}

Researcher, Department of Transport Engineering and Infrastructure, Polytechnic

University of Valencia, Spain

Pablo Salvador Zuriaga

Researcher, Department of Transport Engineering and Infrastructure, Polytechnic

University of Valencia, Spain

\begin{abstract}
Nowadays one of the main priorities for metro line operators is the reduction of energy consumption, due to the environmental impact and economic cost. In order to achieve this objective different strategies can be applied, normally focused into rolling stock, infrastructure and/or operation.
\end{abstract}

Considering short-term measures and related to the traffic operation strategies, different approaches are being researched. One of the most effective strategy which reduce net energy consumption is the use of efficient driving techniques. These techniques produces a speed profile between two stations that requires the minimum net energy consumption, without degrading commercial running times or passenger comfort.

In this paper, a computer model for calculating the metro vehicles speed profiles minimizing the energy consumption was developed. The equations considered in the model represent the behavior of a single vehicle operated under manual driving, subject to different constraints such as the headway, cycle time, distances and acceleration limits. The proposed model calculates different commands to be systematically executed by the driver.

The resulting simulator has been tuned by means of on board measurements of speed, accelerations and energy consumption obtained along different lines in Metro de Valencia network. For this purpose, different scenarios are analyzed to assess the achievable energy savings. In general terms and comparing with the actual energy consumption, the solutions proposed can reduce the net energy consumption around $19 \%$.

\section{INTRODUCTION}

Nowadays metros systems are playing important roles in modern cities. Since metro systems consume huge amounts of energy each day, reducing the intensity of traction energy cost can lead to great economic growth and environmental protection benefits.

In order to reduce traction energy, two main methods are timetable optimization and energyefficient driving (eco-driving). On the first case, considering that most trains are equipped 
with regenerative-braking systems, timetable optimization is focused on synchronize the movement of trains to reduce the global energy consumption from substations by maximizing the use of regenerative energy. The optimization is based on the practice that the acceleration consumes energy from the substation whereas the braking returns energy. A large number of timetable optimization models have been developed with different objectives, such as trip time (Szpigel, 1973), passenger waiting time (Nachtigall, 1997), transport demand (Cordonea and Redaelli, 2011), energy consumption (Nourbakhsh and Ouyang, 2010), delay time (Liebchena et al. 2010), reliability (Salicrùa et al. 2011), operation cost (Li et al. 2013), and robustness (Cacchiani and Toth, 2012). However, most of these techniques only considered the determination of the optimal timetable without some disturbances, which are very frequently and modifies substantially the effectivity of the solution.

On the other hand, the objective in eco-driving techniques is the reduction of the traction energy by optimizing speed profiles. The optimal speed contains an effective combination of four basic train regimes: acceleration, cruising at constant speed, coasting and deceleration. Therefore, an eco-drive consists in selecting a speed profiles that ensures the trip distance and final time between two consecutive stations, but with lower energy consumption.

As previously, an important number of projects and test were been developed in terms of speed profiles (Asnis et al. 1985, Calderaro et al. 2014 and Gong et al. 2014), manual driving for freight trains (Lukaszewicz, 2001), genetic algorithms (Khmelnitsky 2000 and Bigharaz et al. 2014) and high speed driving speed profiles (Sicre et al. 2012). In addition, other recent researches were focused on the use of energy storage systems (Fournier, 2014 and Wang et al. 2014).

Unlike the above studies, the motivation for this work is to approach reduction in traction energy on an experimental approach. Therefore, an energy measurement system is presented, which acquires the most important quantities on-board the train, as a first step to determine the best approach to reduce energy consumption. Then an algorithm based on simulation of the single train motion is proposed in order to design optimal speed profiles, considering the regenerative braking energy. The algorithm has been constructed and validated with real measures obtained.

\section{CHARACTERISATION AND ENERGY FLOW OF VALENCIA METRO NETWORK}

Energy costs represent a considerable financial burden for transport companies, and after staff is the second largest budget item for operators. The energy consumption on metropolitan rail networks consists of two principal aspects: the traction energy for the tractions of its trains and the additional energy to supply systems and for example, lightening 
or elevators in stations, energy for depots, and so forth.

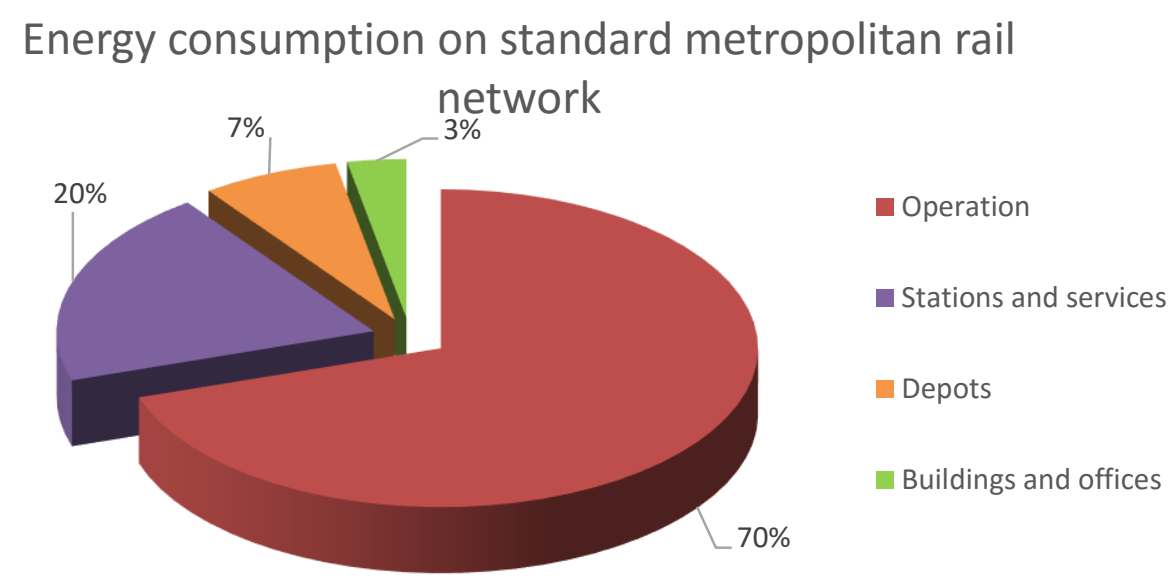

\section{Figure 1: Energy consumption on metro network system}

As illustrated in the Figure 1, the share of the traction energy is normally much more than half of the total energy consumption. For each rail network, the traction energy consumption is determined by many dynamic factors such as driving techniques, characteristics of the trains, alignments and natural environment of the tracks, operation management, etc.

\subsection{Valencia metro network}

Valencia metro operator agency is called Ferrocarrils de la Generalitat Valenciana (FGV), which operates nine narrow-gauge lines (equal to $1000 \mathrm{~mm}$ ). Its network consists of more than $156 \mathrm{~km}$, of which around $27 \mathrm{~km}$ is underground. The tension in metro lines are $1500 \mathrm{~V}$ DC and total annual energy consumption is around $64.5 \mathrm{GWh}$.



Figure 2: FGV metro city network. Source: FGV. 
The Valencia metro network is operated under automatic train protection system, also called ATP. The ATP is formed by the system and all equipment responsible for basic safety. This system avoids collisions, red signal overrunning and exceeding speed limits by applying brakes automatically.

In addition, the underground section of the lines (which represents around $17 \%$ of the total length) are equipped with automatic train operation (ATO), in which responsibility for operation management of the trains is transferred from the driver to the train control system. The ATO system performs all the functions of the driver, except for door closing. The driver only needs to close the doors, and if the way is clear, the train will automatically proceed to the next station. For each inter-station, a set of four speed commands are possible, obtaining four different travel times and energy consumptions. In this work, only ATP segments will be analyzed and performed due that ATO system incorporates some operational and technical constraints that have not been able to study.

\subsubsection{Rolling stock}

The metro Valencia lines are based on the Vossloh 4300 series, composed by four or five cars (Figure 2). As regards the maximum operation performances, it is able to reach a maximum speed equal to $80 \mathrm{~km} / \mathrm{h}$, with acceleration and deceleration maximum rates of $1.1 \mathrm{~m} / \mathrm{s}^{2}$ and $1.2 \mathrm{~m} / \mathrm{s}^{2}$, respectively. Other principal characteristics, for the four carriages unit, are summarized in Table 1.

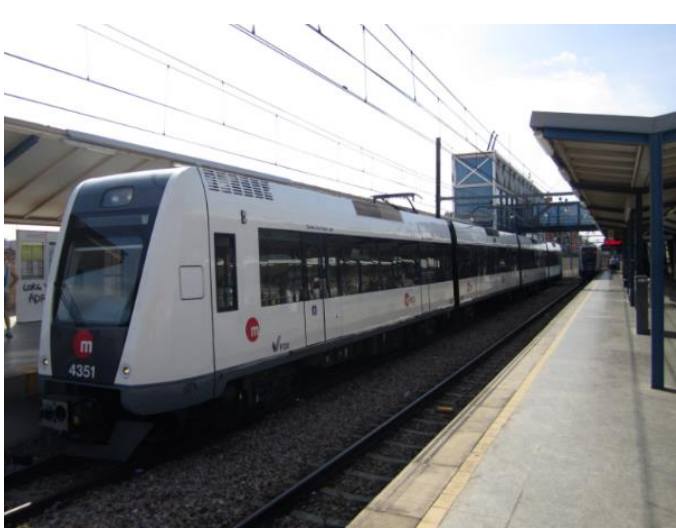

Figure 2: Vossloh 4300 unit on FGV metro network system

\begin{tabular}{|l|l|}
\hline \multicolumn{2}{|c|}{ Rolling stock (Vossloh series 4300) } \\
\hline Tension & $1.500 \mathrm{~V} \mathrm{DC}$ \\
\hline Total traction power & $1480 \mathrm{~kW}$ \\
\hline Weight & $122,85 \mathrm{t}$ \\
\hline Length & $60,49 \mathrm{~m}$ \\
\hline Composition & M-R-R-M \\
\hline Capacity & 588 passengers (116 seating and 472 standings) \\
\hline
\end{tabular}

Table 1 - Rolling stock characteristics 


\section{ENERGY MEASUREMENT CAMPAIGN}

Despite urban rail operators' desire to measure the energy consumption of its rolling stock, a standardized measurement procedure is not yet fully implemented to assist with this process.

In order to gather reliable data for the analysis of energy consumption optimization, three monitoring devices were installed on a single metro train operating in the Metro Network of Valencia. The devices were three DC voltage and current measuring systems (Figure 3) developed by Mors Smitt (model MSAV-DC).

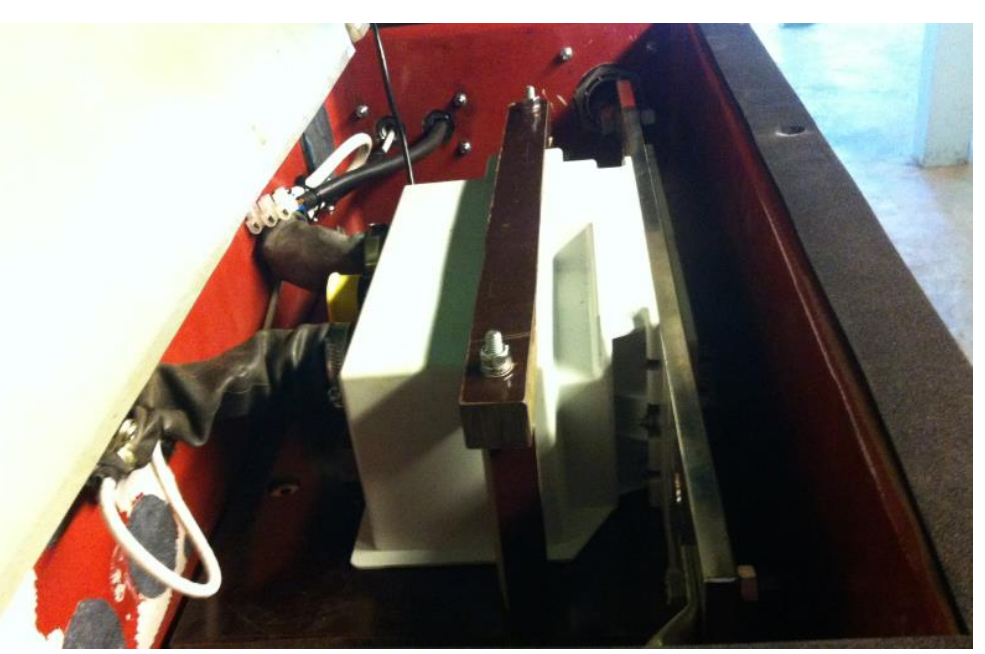

Figure 3: DC voltage and current measuring device installed on metro roof

These devices were placed in the train so as to measure the main energy consumptions, including the overall energy transmitted from the catenary to the train (energy consumed) and backwards (energy regenerated), the train auxiliary systems (i.e. heating, lights, automatic doors, etc.) and the energy consumed by the rheostatic braking system according to European Standards (EN-50463). The sampling frequency of the electric devices is $1 \mathrm{~Hz}$, while the speed was measured at $100 \mathrm{~Hz}$. All the data gathered from these devices was stored in a laptop placed in the train cabin. Additionally, the train speed was measured by means of an odometer and stored in the same laptop.

Once the train was equipped, an extensive monitoring campaign was carried out. The monitored train operated normally for several days along lines 1, 3, 5 and 7. Up to 229 train services were monitored; accounting for more than 230 hours of data.

Data processing was carried out by means of an ad hoc algorithm developed in Matlab. This algorithm synchronised all the datasets and calculated different statistical parameters such as total distance, time, total energy consumed and returned in the catenary, total energy consumed in the resistors and auxiliary systems, mean speed and mean energy consumption. 


\section{ENERGY CONSUMPTION MODEL}

Energy-efficient train operations is a very difficult optimization problem due that timetables and speed profiles should be controlled to reduce the tractive energy consumption under dynamic constraints such as speed limits, train interactions, travel times and distances. To maintain the actual level of service, actual travel times between two consecutive stations have not been modified.

The model developed is based on step-by-step simulation, dividing the train movement into a succession of steps which duration is the time step itself. During each step, the acceleration is considered as constant and variables at the end of a step can be obtained from the values calculated at the beginning of it.

The model includes three independent modules (train dynamics, motor, and energy consumption), with an automatic generator of every possible speed profile. All the constraints that can affect the train motion (speed limitations, maximum traction effort, etc.) are included in the simulation model and described below.

\subsection{Train dynamics}

Railway movement is seen as a one-dimensional problem located in the longitudinal direction of the track. The train motion is governed by the Equation (1):

$$
F_{T}-F_{B}-F_{R}-F_{C}-F_{G}=m_{e q} \cdot a
$$

where $F_{T}$ is the traction force from the motors, $F_{B}$ is the braking force, $F_{R}$ is the running resistance, $F_{C}$ is the running resistance when negotiating curves, $F_{G}$ is the gradient resistance, $m_{e q}$ is the equivalent mass of the train (which includes the passenger mass and the rotational inertia of the rotating masses) and $a$ is the train acceleration.

The model developed calculates at each time step the acceleration of the train $(a)$ from the balance of forces expressed in the Equation (1).

\subsection{Traction force}

This term includes the force applied by the motor on the wheels. This force is transmitted to the rail through the wheel-rail contact. The traction force of the motors can be calculated as expressed in Equation (2):

$$
F_{T}=P_{\text {total }} \eta / v
$$

where $P_{\text {total }}$ is the total traction power, $\eta$ is the efficiency of the full traction chain and $v$ is the running speed.

According to Equation (2), the traction force can be very big if the running velocity is low. Nevertheless, the force transmitted through the wheel-rail contact is limited by the adhesion 
of the powered wheelsets. In this case, the manufacturer calculates the maximum traction force for a coefficient of traction of 0.19 , which corresponds to a case where the surfaces in contact are wet. Figure 4 shows the traction curve for the 4300 Vossloh train.

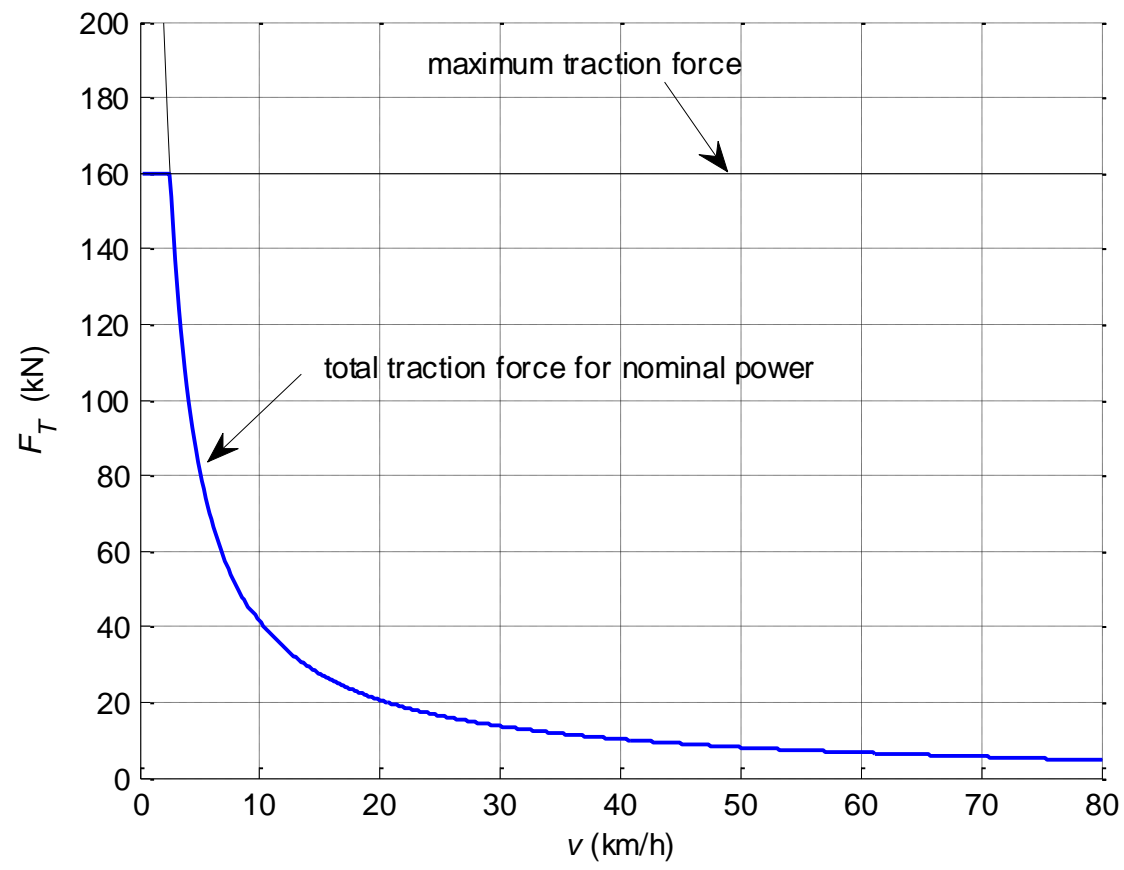

Figure 4: Traction force versus velocity for Vossloh 4300 train

\subsection{Braking force}

This term represents the force applied in order to decrease the speed of the train. The force is transmitted through the wheel and rail interface, so its magnitude, is limited by the adhesion of interfaces, as in the previous case. The 4300 Vossloh train is equipped with dynamic and mechanic brakes. The total braking force is the summation of all the braking systems acting in each moment.

On the one hand, the dynamic braking is performed by the motors; so the braking force is calculated following the model in Equation (2), but with an opposite sign. Then, the dynamic braking power is limited by the total power of the motors and the dynamic braking force by the adhesion in the wheel-rail interfaces for the powered wheelsets. When the motors are acting as brakes, the recovered energy can be either returned to the overhead power supply lines or dissipated in resistances (braking resistances), depending on the conditions of the traffic. It is assumed that the maximum dissipated power in the braking resistances is equal to the total traction power of the motors.

On the other hand, the mechanic braking is applied by a pneumatic circuit, and it acts on all the wheelsets. No limit is considered for the dissipated power on these brakes, but the total mechanic braking force is limited by the adhesion of all the wheelsets of the train. 


\subsection{Running resistance}

Running resistance is the summation of different forces caused by many factors and impede the forward motion of a train. Normally is obtained by adding all individual elements together and it can be calculated as shown in Equation (3).

$$
F_{R}=A+B \cdot v+C \cdot v^{2}
$$

where $A, B, C$ are positive constants for a specific train and v is train velocity. $A, B$ and $C$ are usually obtained from field tests. In this study, values are provided by the manufacturer of the unit.

\subsection{Curve resistance}

This term represents the resistant force which appears on the wheelsets of the train, when traversing a curve. When a train runs on a curved section its instantaneous moving direction is tangent to the curve and different external forces act on the vehicle and on its wheelsets. In this situation, wheelsets try to move laterally on the track and find the radial position whilst primary suspension opposes this movement. Then, extra resistance to motion is experienced by the train, and it is modelled in Equation (4).

$$
F_{C}=k /_{R} \cdot m_{t}
$$

where $k$ is a constant which depends on the track gauge, $R$ is the radius in meters and $m_{t}$ is the total train mass in kilograms.

\subsection{Gradient resistance}

Considering the gravity force, when the plane of the track is inclined two forces can be described: the force along the gradient and the force normal to the incline. The equation that gives the gradient resistance can be expressed as Equation (5).

$$
F_{G}=m_{t} \cdot g \cdot \sin \alpha \cong m_{t} \cdot p_{t} / 1000
$$

where $\alpha$ is the angle of gradient in radians, $g$ is the acceleration of gravity in $\mathrm{m} / \mathrm{s}^{2}$ and $p_{t}$ is the coefficient of grade resistance $(\%)$.

\subsection{Energy consumption}

The estimation of total energy consumption is based on three terms: the energy used by the traction motors, the energy consumption of auxiliary systems, and the energy recovered from regenerative braking. For our purposes only traction and regenerative energy are considered, considering that energy used by auxiliary systems depends basically on travel time. In addition, the energy consumption model with regenerative braking systems usually implies an energy consumption model of the entire line in order to consider regenerate energy used 
by other train in the same electric stretch.

The purpose of this paper is to optimise speed profiles for a single train between two consecutive stations in order to minimise its energy balance. This means that the travel is constrained to its timetable and to the forecasted travel demand. Therefore, the approach to the problem assume line constraints as external constraints, adopting a microsimulation approach.

The energy consumption $(E)$ for single train running along a given track is calculated as the mechanical power delivered by the traction force minus the energy recovered from the dynamic braking, which is returned to the overhead power supply. These two terms are represented in Equation (6).

$$
E=\int F_{T} \cdot v \cdot d t-\int F_{B}^{*} \cdot v \cdot d t
$$

where $F_{B}^{*}$ is the dynamic brake force which is used to regenerate energy to the overhead power supply.

\subsection{Simulation}

The proposed model calculates the energy consumption always meeting comfort criteria between two consecutive stations. The distance switch from the initial state to the final one results in the train movement from one station to the next. Due to the constant acceleration in the period $d t$, the speed will be changed from $v_{i}$ to $v_{i+1}$ and distance will be changed from $x_{i}$ to $x_{i+1}$. The process can be summarized as follows:

1. Parameter inicialization (the parameters of the train and track should be specified).

2. Computation of the resistance forces (running resistance, curve and gradient forces).

3. Comparison of current velocity with maximum velocity (either given by the maximum velocity of the stretch or by a braking curve).

4. Application of traction/braking forces.

5. Calculation of the next position.

6. Return to step 2, if the train has not still reached the station.

The maximum allowed speed at any point of the track is either the profile velocity when braking to a lower target speed or an existing speed limit of the track, whichever is lower, at the current location of the train. So that, when a train approaches to the next station, the velocity is obtained with the help of a velocity profile that provides a speed reduction to reach the station for a safe stop at the target location. 


\section{MODEL VALIDATION}

In order to adjust and validate the simulator, the proposed model was applied to different lines with manual driving of the Valencia metro network under real operative constraints by adjusting the parameters. The results obtained have been compared with measured data registered in the monitoring campaign. The simulated running times differ on average $0.5 \%$ from measured times, and the difference between net energy consumptions less than $2.5 \%$ for all cases, as shown in Table 2.

\begin{tabular}{|l|c|c|c|}
\hline \multicolumn{1}{|c|}{ Stretch } & $\begin{array}{c}\text { Measured values } \\
(\mathrm{kWh})\end{array}$ & $\begin{array}{c}\text { Simulated values } \\
(\mathrm{kWh})\end{array}$ & Error (\%) \\
\hline L1 - Bétera/Seminari CEU & 15.48 & 15.39 & -0.60 \\
\hline L1 - Seminari CEU/Bétera & 53.99 & 54.00 & 0.03 \\
\hline L2 - Líria/Eliana & 17.94 & 18.08 & 0.79 \\
\hline L2 - Eliana/Líria & 31.52 & 31.27 & -0.80 \\
\hline L3 - Rafelbuñol/Almásera & 42.43 & 43.28 & 2.01 \\
\hline L3 - Almásera/Rafelbuñol & 62.48 & 62.12 & -0.58 \\
\hline L7 - Val.Sud/Torrent & 31.95 & 32.68 & 2.26 \\
\hline L7 - Torrent/Val.Sud & 20.01 & 19.92 & -0.42 \\
\hline
\end{tabular}

Table 2: Energy consumption comparison results

\section{DESIGN OF EFFICIENT SPEED PROFILES}

Once validated, the model allow us to compare the speed profiles and energy consumption obtained with real examples, measuring the reduction in energy that model provides.

To enable the simulation of manual driving strategies, different strategies can be managed with a set of configurable parameters such as acceleration-deceleration rates, coasting criteria and speed restrictions. The most efficient techniques to reduce the energy consumption are holding speed without braking and performing a coasting process before braking to reach a speed limit or a stopping station.

The model executes this commands taking into account the speed and running time constraints. Under these conditions, a wide range of solutions can be obtained and analyzed.

As example, in Figure 6 the real and simulated speed profiles between two stations are reported. The simulation uses the real time travel as input, so the optimized curve does not significantly deviate from the reference run. The result obtained covers the single section length with a total running time of 87 seconds which is the actual running time for this stretch, and the savings in net energy consumption reaches $10 \%$. 


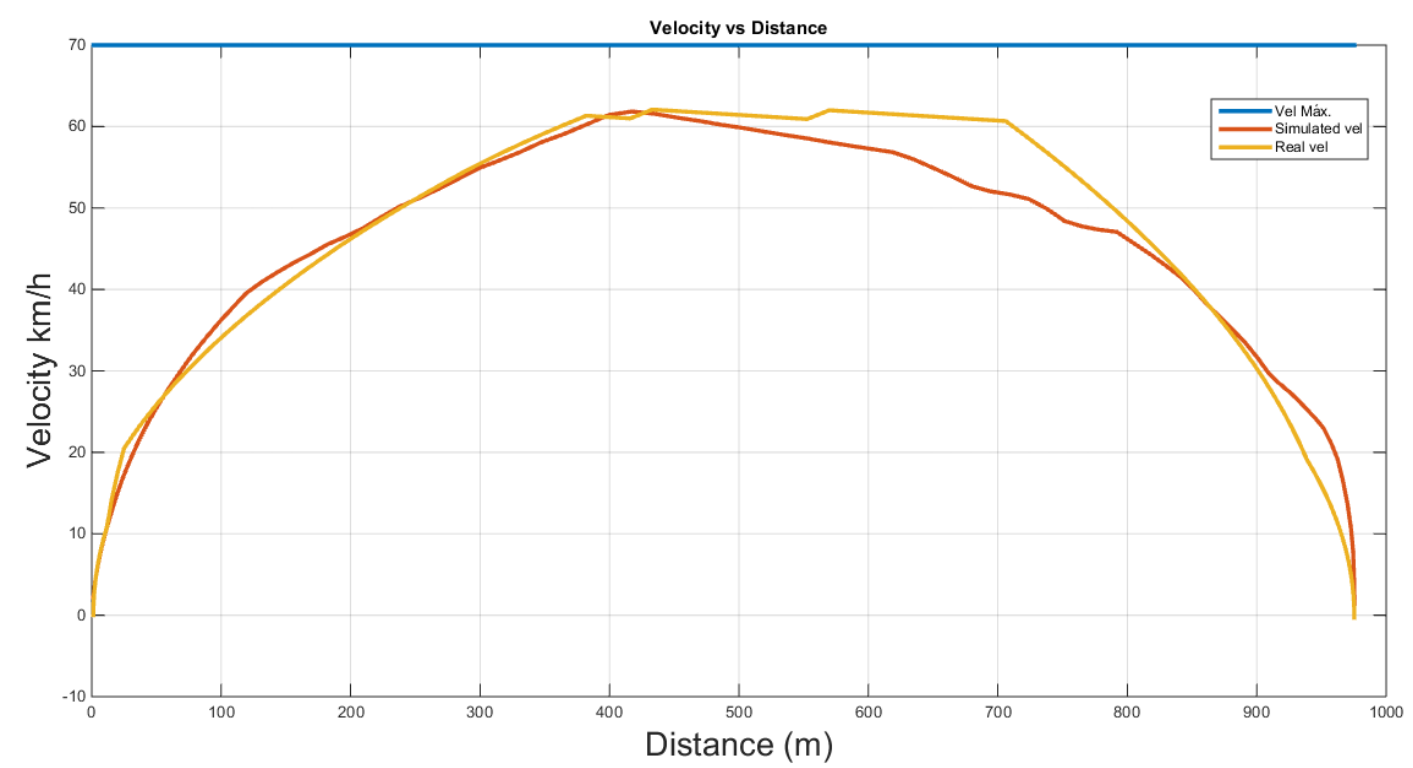

Figure 6. Optimal speed profile (red) versus real speed profile (yellow)

Other results for different lines are showed in Table 3. The energy reduction varies between $16 \%$ and $26 \%$, depending on the track considered. Only in one case of study (L1) the energy optimization has not been possible.

\begin{tabular}{|l|c|c|c|}
\hline \multicolumn{1}{|c|}{ Stretch } & $\begin{array}{c}\text { Real energy } \\
\text { consumption } \\
(\mathrm{kWh})\end{array}$ & $\begin{array}{c}\text { Optimized energy } \\
\text { consumption } \\
(\mathrm{kWh})\end{array}$ & $\begin{array}{c}\text { Energy } \\
\text { reduction } \\
(\%)\end{array}$ \\
\hline \hline L1 - Bétera/S.Psiquiàtric & 4.23 & 4.23 & 0.00 \\
\hline L1 - S.Psiquiàtric/Bétera & 10.24 & 7.52 & 26.78 \\
\hline L2 - Llíria-Benaguasil 2n & 7.41 & 5.88 & 20.59 \\
\hline L2 - Benaguasil 2n-Llíria & 9.99 & 7.87 & 21.23 \\
\hline L3 - P.Farnals-Massamagrell & 4.20 & 3.33 & 20.66 \\
\hline L3 - Foios-Meliana & 6.12 & 4.65 & 23.95 \\
\hline L7 - Val.Sud-Paiporta & 5.38 & 4.50 & 16.59 \\
\hline L7 - Paiporta-Val.Sud & 4.91 & 3.95 & 19.48 \\
\hline
\end{tabular}

\section{Table 3. Energy savings obtained}

\section{CONCLUSIONS}

Previous works have already highlighted the importance of the optimal design of speed profiles, taking into account timetable constraints. In this paper a model is proposed for the design speed profiles to minimize the energy consumption in the Valencia metro network under manual driving.

The tool presented is based on a mechanical and an electrical model. The mechanical model recalculates train speed and position in every simulation step. The acceleration parameter is obtained through the traction force, the aerodynamic resistance, the track gradient and curvature resistance, the braking force and the dynamic train mass. 
The energy consumption is calculated knowing the traction force and the speed in all simulation steps. During the braking process is also possible to determine the energy recovered in the train.

Finally, the model proposed was tested on a real-scale case involving a suburban line. The simulations have shown to obtain a great reduction in the consumption of net energy of around $16-26 \%$.

\section{ACKNOWLEDGEMENTS}

The authors wish to thank Ferrocarrils de la Generalitat Valenciana (FGV) for their kind support during the development of this study, including their assistance during the installation of the consumption devices aboard their trains and their permission to carry out measurements during the normal service.

This project has by funded by the Spanish Ministry of Economy and Competitiveness (Ref. TRA2011-26602).

\section{REFERENCES}

[1] ASNIS, I.A. DMITRUK, A.V. and OSMOLOVSHII, N. P. (1985) "Solution of the problem of the energetically optimal control of the motion of a train by the maximum principle", USSR Comput. Math. Math. Phys., 25, 37-44.

[2] BIGHARAZ M. H. et al. (2014). "Simultaneous Optimization of Energy Consumption and Train Performances in Electric Railway Systems”. 19th IFAC World Congress, Cape Town, South Africa. August 24-29, 2014.

[3] CACCHIANI, V. and TOTH, P. (2012) "Nominal and robust train timetabling problems," Eur. J. Oper. Res., vol. 219, no. 3, pp. 727-737.

[4] CALDERARO V. et al. (2014) "An Algorithm to Optimize Speed Profiles of the Metro Vehicles for Minimizing Energy Consumption", International Symposium on Power Electronics, Electrical Drives, Automation and Motion (SPEEDAM 2014), Ischia, Italy.

[5] CORDONEA, R. and REDAELLI, F. (2011) "Optimizing the demand captured by a railway system with a regular timetable," Transp. Res. B, Methodol., vol. 45, no. 2, pp. 430-446.

[6] FOURNIER, D. (2014) "Metro Regenerative Braking Energy Optimization through Rescheduling: Mathematical Model and Greedy Heuristics Compared to MILP and CMA-ES" Computer Science. Paris-VIII <tel-01102408>.

[7] GONG, C. et al. (2014). "An Integrated Energy-Efficient Operation Methodology for Metro Systems Based on a Real Case of Shanghai Metro Line One" Energies 7, no. 11: 7305-7329. 
[8] KHMELNITSKY, E (2000). "On an Optimal Control Problem of Train Operation". IEEE Transactions on automatic control, vol. 45, no. 7, July 2000.

[9] LI, X. WANG, D. LI, K. and GAO, Z. (2013) "A green train scheduling model and fuzzy multi-objective optimization algorithm," Appl. Math. Model, vol. 37, no. 4, pp. 2063-2073.

[10] LIEBCHENA, C. SCHACHTEBECKB, M. SCHÖBEL, A. STILLER, S. and PRIGGE, A. (2010) "Computing delay resistant railway timetables," Comput. Oper. Res., vol. 37, no. 5, pp. 857-868.

[11] LUKASZEWICZ, P. (2001). "Energy Consumption and Running Time for Trains". Royal Institute of Technology KTH, June 2001; Stockholm.

[12] NOURBAKHSH S. M. and OUYANG, Y. (2010) "Optimal fueling strategies for locomotive fleets in railroad networks," Transp. Res. B, Methodol. vol. 44, no. 8/9, pp. $1104-1114$

[13] SALICRÙA, M. FLEURENTB, C. and ARMENGOLC, J. M. (2011) “Timetablebased operation in urban transport: Run-time optimisation and improvements in the operating process,” Transp. Res. A, Pol., vol. 45, no. 8, pp. 721-740.

[14] SICRE, C. et al. (2012). "Modelling and optimizing energy-efficient manual driving on high-speed lines", IEEJ Transactions on Electrical and Electronic Engineering. vol. 7, no. 6, pp. 633-640, November 2012.

[15] WANG Y. et al. (2014) "An Improved Genetic Algorithm for Optimal Stationary Energy Storage System Locating and Sizing”. Energies 2014, 7, 6434-6458. 